\title{
Influence of Clay Minerals Nature on the Hydromechanical and Fracture Behaviour of Stones
}

\author{
Mathilde Tiennot ${ }^{1,2,3} \cdot$ Jean-Didier Mertz ${ }^{2,3} \cdot$ Ann Bourgès ${ }^{2,3}$
}

Received: 24 April 2018 / Accepted: 19 November 2018 / Published online: 22 January 2019

(c) The Author(s) 2019

\begin{abstract}
Elastic properties and fracture behaviour evolutions of two sedimentary stones are under study to estimate their influence on scaling effect of monumental stone heritage. Young moduli and toughness of Villarlod molasse and Thüringer sandstone are measured under moisture content variations with respect to their natural anisotropy. Several relative humidity levels are considered to investigate their effect upon humidification and drying. The stone property evolution is in close correlation with the identified clay phases of the matrix. It appears that clay minerals as smectite and glauconite influence the stone properties at very low moisture contents, whereas less swelling clays have impact only when high moisture contents are reached. This is in close correlation with the inherent deformation ability of these minerals. It is observed that nature and distribution of clay phases largely influence on the macroscopic behaviour under natural exposure conditions, as they modify the stone properties and represent the weakness planes of the stone.
\end{abstract}

Keywords Toughness anisotropy $\cdot$ SCB testing $\cdot$ Clays nature $\cdot$ Swelling ability $\cdot$ Oriented microcracking

\section{Introduction}

A large diversity of degradation patterns can be observed on monumental stone heritage (ICOMOS 2008). Various mechanisms as biocolonization, salt crystallisation, thermal and freeze-thraw cycling and especially water effect can be involved in stone alteration. Several studies illustrate the impact of water and moisture content on this degradation, as it implies repeated dimensional hydric (liquid water) or hygric (moisture content) swelling variations that may have many consequences on the long-term stability of stones. Moreover, water influences the mechanical and fracture behaviour of magmatic as well as sedimentary stones.

One of these alteration patterns is the scaling effect, widely observed on various stones, for instance, on Villarlod

Mathilde Tiennot

mathilde.tiennot@gmail.com

1 Present Address: ESPCI Paris, SIMM Laboratory, 10 rue Vauquelin, 75005 Paris, France

2 Laboratoire de Recherche des Monuments Historiques, 29 rue de Paris, 77420 Champ-sur-Marne, France

3 Sorbonne Universités, Centre de Recherche sur la Conservation (CRC, USR 3224), MNHN-MCC-CNRS, 36 rue Geoffroy-Saint-Hilaire, 75005 Paris, France molasse (Fig. 1). When the surface of the stone is exposed to natural variations of relative humidity $(\mathrm{RH})$ and to liquid water, a contour scaling may develop parallel to the surface, at a few millimeter depth. It results from the repeated solicitation of the stone and from the evolution of its ability to withstand initiation and propagation of a crack. To understand this phenomenon, the hydromechanical behaviour of the stone is under study, and a specific fracture mechanics approach is proposed.

Over the past few years, several researches presented the evolution of the mechanical properties with water content. First, water transport has consequence on the elastic properties of the stone. Water induces a stiffness loss, measured using static and dynamic methods. Previous studies presented the decrease of Young modulus E with water and RH variations, some of them with respect to the anisotropy of the natural material (Sarout 2006; Vasarhelyi 2003; Erguler and Ulusay 2009). Some researches on modulus loss are also carried out to specifically understand the decay of cultural heritage stones (Felix 1977; Scherer and Jiménez González 2005; Wangler and Scherer 2008). Young moduli measurements are then integrated on stress induced by swelling calculus (Scherer and Jiménez González 2005; Tiennot 2017).

Tensile and compression strength resistance evolution with water or RH is also of great interest to figure out the 


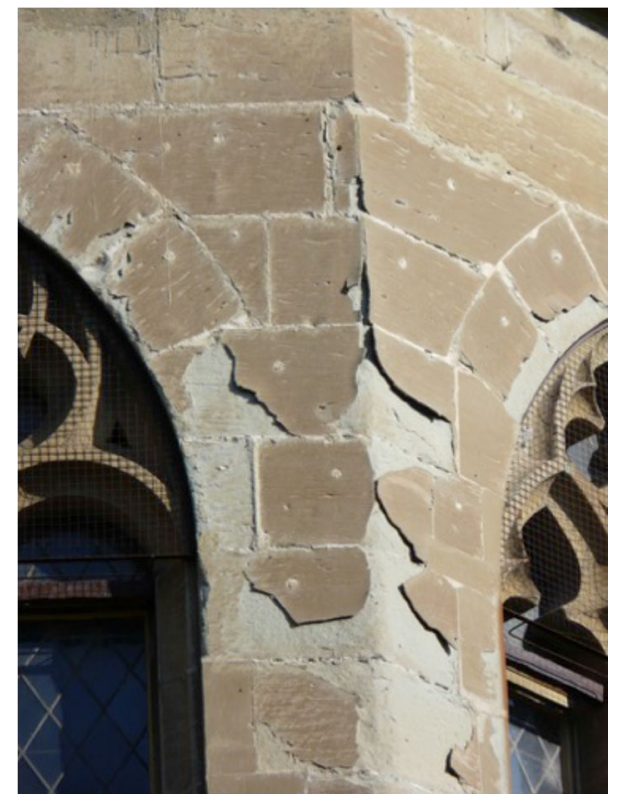

Fig. 1 Contour scaling pattern developing on Villarlod molasse at the Fribourg city hall

stone degradation factors. Even little water content can induce a huge decrease, up to $80 \%$, of compressive strength (Van Eeckhout 1976; Hawkins and McConnell 1992; Erguler and Ulusay 2009).

Fracture behaviour and toughness of magmatic and sedimentary stones are influenced by environmental conditions as well (Utagawa et al. 1999; Nara et al. 2011). (Kuruppu et al. 2010) illustrate the decrease of toughness with respect to the natural orientation of the anisotropic studied granite. This phenomenon is correlated with the crack tip condensation effect (Atkinson 1980; Meredith and Atkinson 1983).

Moreover, influence of clay phases on cracking is often highlighted. For instance, the specific presence of smectite within the stone is put forward by Burshtein (1969) and Nara et al. (2012) as involved in the decrease of the stone strength, and by Nara et al. (2011) and Funatsu et al. (2004) as an essential factor on the decrease of toughness. This is in close correlation with the swelling ability of smectite, inducing tensile stresses at the crack tip.

Thus, interactions between water and stone depend on the texture, the fabric, the open porosity, and the mineralogical composition. They are largely influenced by the amount, nature, and distribution of the stone phases, especially clay minerals, which are sensitive to water (Franzen and Mirwald 2004; Siegesmund and Snethlage 2011; Wangler and Scherer 2008).

Based on these previous researches, this study investigates the specific influence of clay minerals nature on the hydromechanical and fracture behaviour of two sedimentary stones, the Villarlod molasse and the Thüringer sandstone. Their anisotropic swelling ability is studied and correlated with the sensitive phases. The evolution of both elastic moduli and fracture toughness with RH variations is evaluated with respect to the natural anisotropy of the stones. The aim is to estimate the influence of moisture content and its variations on the evolution of the mechanical properties. Several conditions of relative humidity are selected-33\%, 65\%, and 97\%-as they are relevant with the natural exposure conditions a monumental stone could suffer. Cracks paths followed within the various phases are finally studied. Influence of clay minerals on the crack initiation and propagation, and on the macroscopic and microscopic behaviour, is discussed.

\section{Materials and Methodologies}

\subsection{Stone Materials and Sampling}

The first clay-bearing stone under study is the Villarlod molasse, from the Burdigalien formation, extracted from the Fribourg region (Switzerland), where it is used as a traditional building material (Felix 1983). Typical decay of this stone is related to small scales around $1 \mathrm{~cm}$ thick (Fig. 1). Scaling effect of this specific stone has been under study for several years (Felix 1977; Felix et al. 2000).

The second sedimentary clay-bearing stone considered for this research is the Thüringer sandstone, known as Schilfsandstein from the Superior Trias. This stone has also been used as monumental material, for instance, at the Drei Castle (Stück 2013).

The supposed anisotropy due to the natural bedding plane of these to sedimentary stones is identified by measuring the elastic wave propagation velocities in the three directions of blocks $\left(35 \times 35 \times 35 \mathrm{~cm}^{2}\right)$ from quarry. Ten measures are carried out on each direction. The lowest value indicates the direction perpendicular to this plane, along the $\mathbf{e}_{\mathbf{n}}$ axis. The highest velocity helps to identify the preferred orientation of minerals and inherent microcracks along $\mathbf{e}_{\mathbf{t}}$. As $V_{t}$ and $V_{l}$ are close, the two rocks are considered isotropic transverse. Plugs of $40 \mathrm{~mm}$ in diameter and $80 \mathrm{~mm}$ in length are cored from blocks in the two principal directions of the stone (Fig. 2). They are designed as perpendicular and parallel samples.

Samples of sedimentary rock may present heterogeneities due to the fabrics and mineralogical composition. They may influence the mechanical properties (Baecher and Einstein 1961; Guy et al. 2018). Wave propagation measurements on the set of samples confirm that cores and specimens used for experimental testings are homogeneous. No macroscopic scattering is identified (Table 1). 


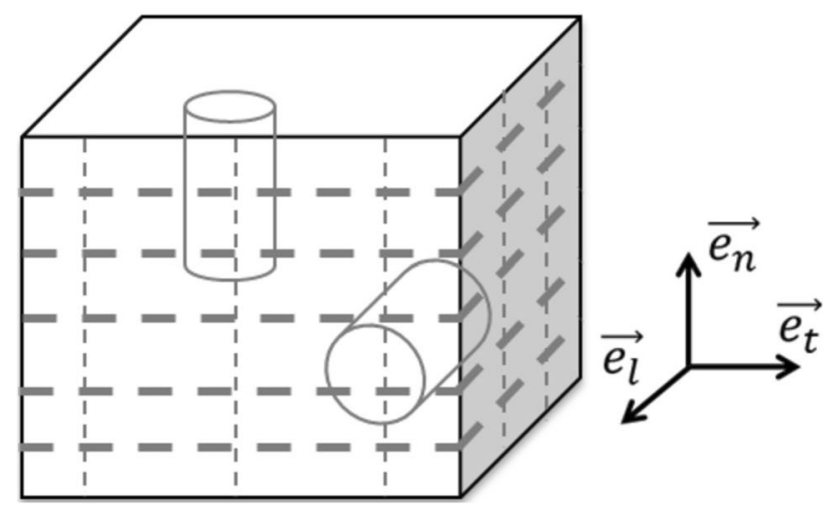

Fig. 2 Natural orientation of minerals and of inherent microcracks within the sedimentary stones

Table 1 Wave propagation velocity along the three directions of the bloc of Villarlod molasse and Thüringen sandstone

\begin{tabular}{llll}
\hline$V\left(\mathrm{~m} \mathrm{~s}^{-1}\right)$ & $V_{l}$ & $V_{t}$ & $V_{n}$ \\
\hline Molasse & $1705(42)$ & $1590(40)$ & $1313(38)$ \\
Sandstone & $2623(40)$ & $2650(32)$ & $2553(64)$ \\
\hline
\end{tabular}

\subsection{Characterization}

Mineralogical composition and microstructural properties are studied. Particular attention is paid to clay minerals identification by X-ray diffraction (XRD) using a Brücker D8 Advance ${ }^{\circledR}$ Bragg-Brentano diffractometer. Extraction of clay fraction is performed for the two sedimentary stones, followed by two treatments on natural clay fraction: a $490{ }^{\circ} \mathrm{C}$ oven heating during $4 \mathrm{~h}$ and a conditioning in ethylene glycol saturated atmosphere. Identification of mineralogical phases is confirmed by optical microscopy (OM) and observations of fresh fractures by FESEM observations. Relative orientation and organization of the phases are observed, and the open porosity is measured by Mercury Injection Porosimetry (MIP) (ASTM 2010). Total porosity and pore size distribution are quantified.

\subsection{Mechanical Behaviour}

Elastic properties of the molasse and the sandstone are measured to study the potential modification induced by the various exposure conditions at fixed RH during humidification and drying. A specific choice of a non-destructive acoustical method results from a large number of the previous researches, indicating that dynamic methods can measure the elastic Young moduli of stones even if differences may appear with static mechanical results (Homand et al. 1993; Amadei 1996). Non-destructive dynamical testings of moduli are developed in cultural heritage field as only few samples can be cored on monuments. As relative differences are evaluated in this research-between the two stones, the two principal directions and under RH variations-acoustic method seems relevant for this analysis. A GrindoSonic $^{\circledR}$ device is used for the testing. The measurement is based on two modes resonance frequencies on cores of $40 \mathrm{~mm}$ in diameter. This core geometry is appropriate for such dynamical testing (Siggins 1993). As wave propagation velocities in materials are related to the elasticity constants through the Christoffel's equation, the Young moduli can be measured (Sarout 2006). A plane of transverse isotropy has been identified for the two sedimentary stones, so only five components of the stiffness matrix are required to characterize the material (Amadei 1996; Aristégui and Baste 1997). Thus, only two moduli are measured, perpendicular and parallel to the bedding plane, plane of transverse isotropy. The transverse samples prepared perpendicular to the natural bedding plane allow to measure $E_{n}$, while axial samples parallel to the plane give $E_{t}$ (Homand et al. 1993). Evolution of these two moduli with various conditions is under study. Eight samples cored on both directions are tested using this non-destructive method.

To evaluate the influence of $\mathrm{RH}$ variations on the mechanical and fracture behaviour, fracture toughness is also measured under various exposure conditions (presented in the section below). Samples adapted for cultural heritage studies have been proposed thanks to the previous investigations (Tiennot and Bourgès 2016; Tiennot 2017). Semicircular Bending (SCB) samples are used for this research. They are prepared from the cores of $40 \mathrm{~mm}$ in diameter. Several researches used this method in geomaterial field (Lim et al. 1993; Tutluoglu and Keles 2011), where the sample is loaded under a three-point bending. The semi-circular specimen is sliced such as the thickness $t$ is equal to the radius $R$, so $t / R=1$ (Lim et al. 1993). An initial notch of length $a$ is prepared using a diamond saw and its final dimensions are 1 $\mathrm{mm}$ in width and $4 \mathrm{~mm}$ in length (Fig. 3). This initial notch length is fixed, so that $a / R=0.2$. The distance between the two rollers is fixed as $S / R=0.6$

The notch is not sharpened to study the minerals in which the initiation occurs, because it seems more representative of the natural conditions (Tiennot 2017).

As the only mode I is considered, the initial notch is straight aligned with the loading direction (Fig. 3). For these SCB samples, the stress intensity factor is calculated using the expression (1) depending on the applied stress $\sigma$, the initial notch length $a$, and a geometrical factor $Y$, depending of the sample geometry:

$K_{\mathrm{I}}=Y \sigma \sqrt{\pi a}$

with

$\sigma=\frac{F}{2 R t}$, 
Fig. 3 SCB specimen on the three-point bending device after crack initiation and propagation
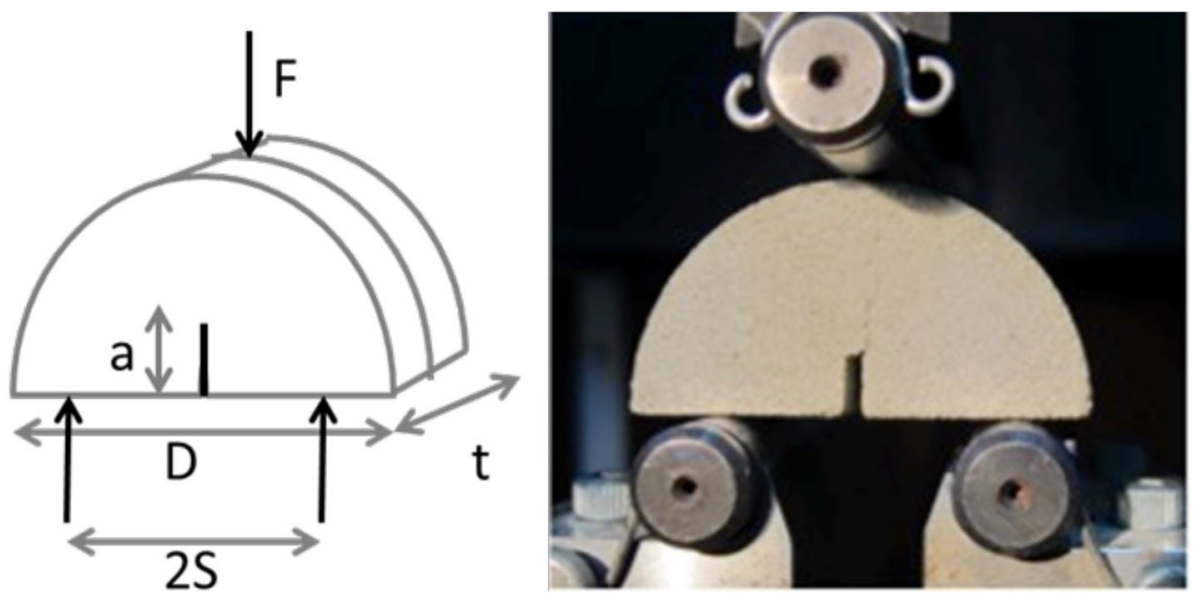

where $F$ is the applied force, $R$ is the radius, and $t$ is the thickness of the sample.

For the used parameter $S / R=0.6, t / R=1$, and $a / R=0.2$, Lim et al. (1993) calculated the value $Y=3.260$. Knowing the maximum loading of the specimen allows calculating the critical stress intensity factor in mode I, the toughness $K_{\mathrm{IC}}$.

The aim of this research is to better understand the fracture behaviour of two sedimentary stones. Thus, toughness has to be measured with respect to the natural minerals orientation. The identified plane of transverse isotropy is related to the natural bedding plane of the Villarlod molasse and the Thüringen sandstone. Three configurations of toughness measurements with respect to this plane are described in Fig. 4. Perpendicular SCBperp configuration is prepared using plugs cored along $\mathbf{e}_{\mathbf{n}}$. SCBt and SCBn samples are sliced on cores along the bedding plane. For SCBn and SCBt configuration, the initial notch required is, respectively, orthogonal and along the preferred orientation of minerals and microcracks along $\mathbf{e}_{\mathbf{t}}$ (Fig. 4).

Fig. 4 Fracture toughness measurements using SCB specimens, with respect to the natural heterogeneity of the material

\subsection{Exposing Conditions to Estimate the Swelling Influence on the Mechanical Behaviour}

Hygric swelling ability of the two stones is measured using the dilatometric system adapted at the laboratory (Mertz et al. 2012) on the two directions perpendicular and parallel to the bedding plane. Dimensional behaviour is measured by LVDT sensors TWK (accuracy $0.3 \mu \mathrm{m}$ ). Free swelling strains are measured under isothermal condition $\left(T=20^{\circ} \mathrm{C}\right)$ from the initial dry state to the choosen $\mathrm{RH}$ level 33-65-97\%, during humidification and drying. Each step within the dilatometric device lasts $96 \mathrm{~h}$ (Fig. 8). These free swelling strains are related to the natural orientation of the inherent microcracks and of the mineralogical phases, especially the clay minerals, sensitive to moisture.

For each testing, the initial state items designed samples oven-dried until constant mass. For elastic moduli and toughness measurements, the humidification phase designed samples first oven-dried and then placed on enclosures saturated at $33 \%, 65 \%$, or $97 \%$ of RH until constant mass. Samples used to characterize the drying phase are first ovendried, then conditioned at $97 \%$ of RH and finally placed on the defined enclosure at $65 \%$ or $33 \%$ of RH until constant

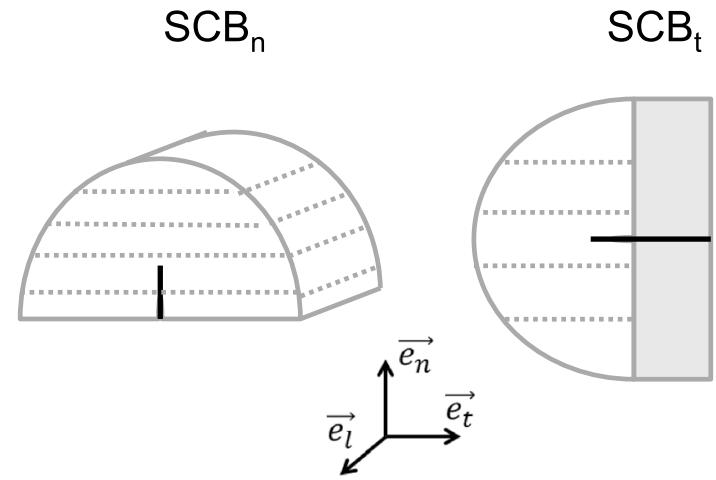

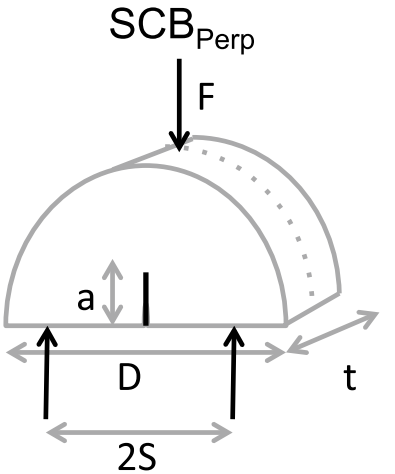


mass. These conditions are relevant with environmental conditions applied on monumental stone.

For each condition, initial dry state and RH levels, four cores parallel and four cores perpendicular are used to measure Young moduli in the two directions. Eight samples $\mathrm{SCBt}, \mathrm{SCBn}$, and SCBperp are used to characterize the two stones at the initial state. Four samples in each configuration are tested for the five RH levels previously defined for the humidification and the drying phase.

\section{Mineralogical and Microstructural Properties}

The mineralogical composition of the two stones is investigated. The identified phases of the Villarlod molasse are coarse grains of quartz, feldspars, biotite, and clay mineral phases within a calcitic and dolomitic matrix (Fig. 5). Wellidentified green spots of glauconite are observed on thin section (Fig. 5). These dispersed particles provide the global green color to the stone and helps to identify the natural orientation of the minerals. The extracted clay fraction under XRD allows to identify the clay minerals as chlorite, glauconite, and smectite. SEM observations inform on the morphology of theses phyllosilicates. Smectite phases are observed at the surface of the other components (Fig. 6). Smectite and glauconite are well-known to have a huge swelling ability and to induce the free swelling of the stone under hydrothermal solicitation.
Coarse grains of quartz and feldspars are also observed in the Thüringen sandstone, associated with muscovite and biotites. Clay phases are identified on FESEM observations and identified by XRD (Fig. 7). These clay minerals are chlorite, kaolinite, illite, as well as mixed layers of chlorite and smectite.

Microstructural properties are characterized at the initial dry state. Open porosity to mercury is measured at 12.6 $(0.25) \%$ for the Villarlod molasse and $13.4(0.80) \%$ for the sandstone. The first stone shows a pore access radius at $2.5 \mu \mathrm{m}$, while the latter shows a bimodal distribution with a first set of pore access radius centered at $0.02 \mu \mathrm{m}$, associated with the clay matrix distribution and the other at $1.5 \mu \mathrm{m}$ associated with the main microcracks porosity. This bimodal porosity is well observed on FESEM images (Fig. 7).

Thus, the two stones show specific microstructural organizations and distributions. Moreover, the identified clay minerals are different and their sensitivity to moisture is quite various. Their impact on swelling, alteration, and evolution of the mechanical behaviour with respect to moisture content is discussed in the next section.

\section{Swelling Behaviour}

The free swelling strains of the two stones are measured at various specific RH states, on cores perpendicular and parallel to the bedding plane (Fig. 8). A macroscopic reversibility of the swelling behaviour over cycles has already
Fig. 5 Observation of thin sections of Villarlod molasse (top) and Thüringen sandstone (bottom) in natural light (left) and polarized light (right)
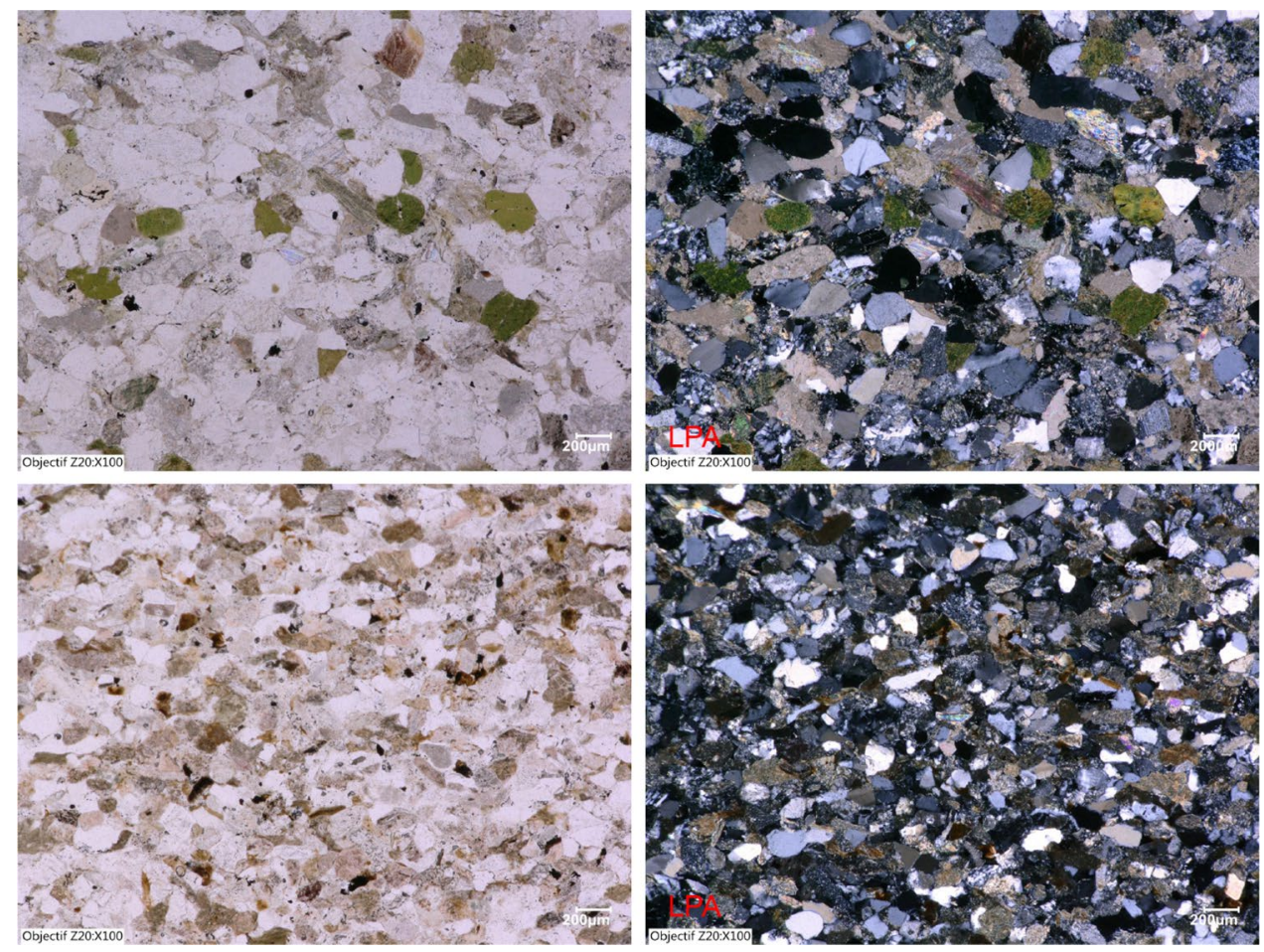


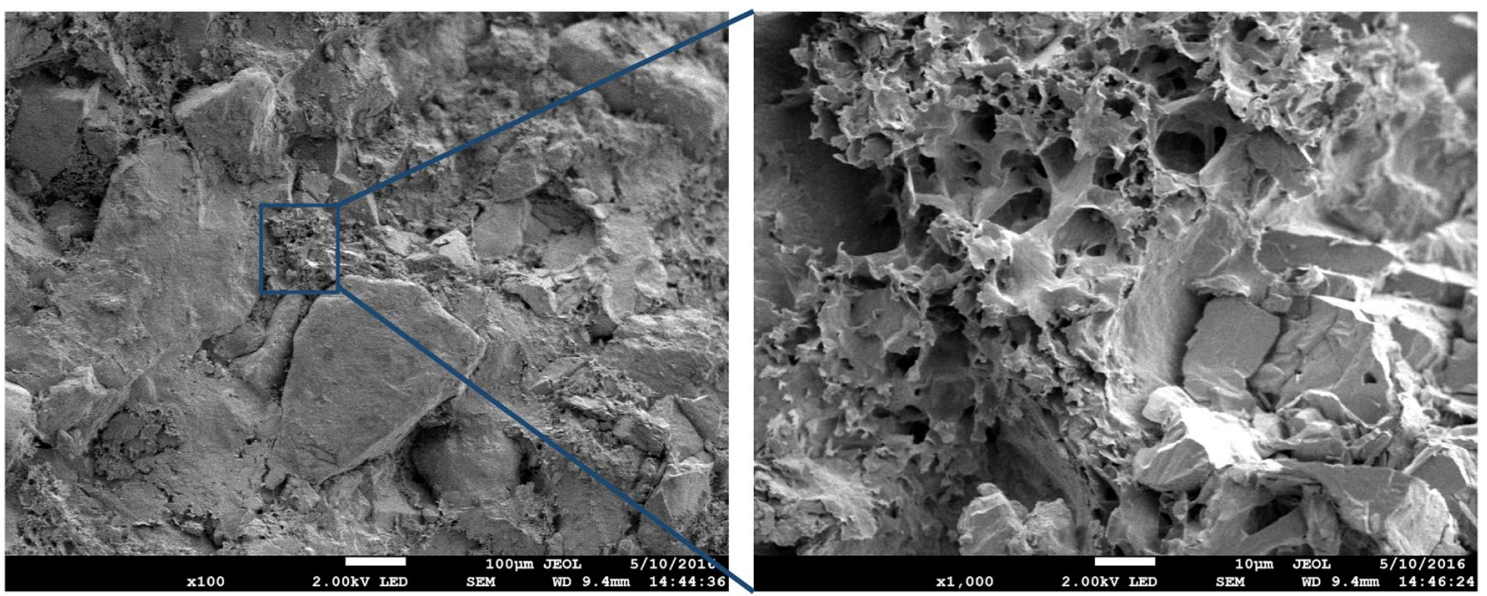

Fig. 6 FESEM observation of the Villarlod molasse: rigid minerals as quartz and feldspars are included in the clay matrix, mainly constituted of smectite
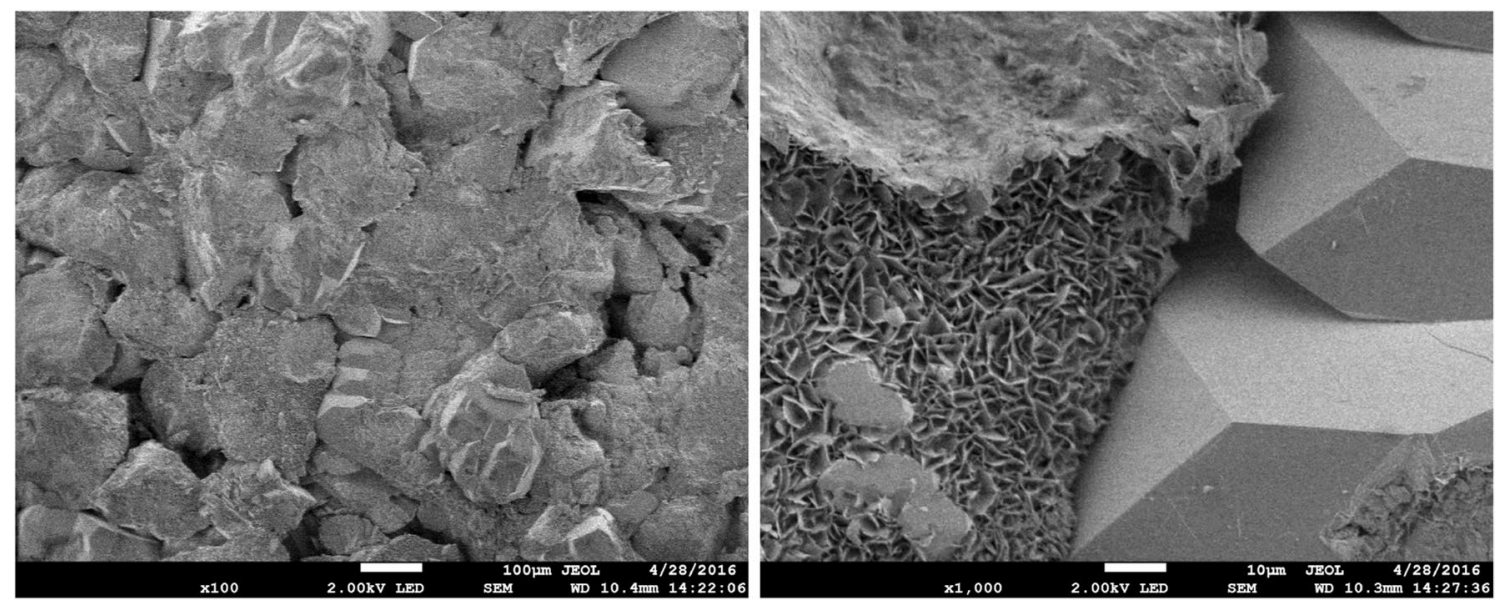

Fig. 7 FESEM observation of the stone: quartz, feldspars and chlorite phases are identified, as well as the bimodal porosity

Fig. 8 Dimensional behaviour of Villarlod molasse in the directions perpendicular and parallel to the natural orientation of minerals during humidification and drying, with stabilization at specific $\mathrm{RH}$ levels

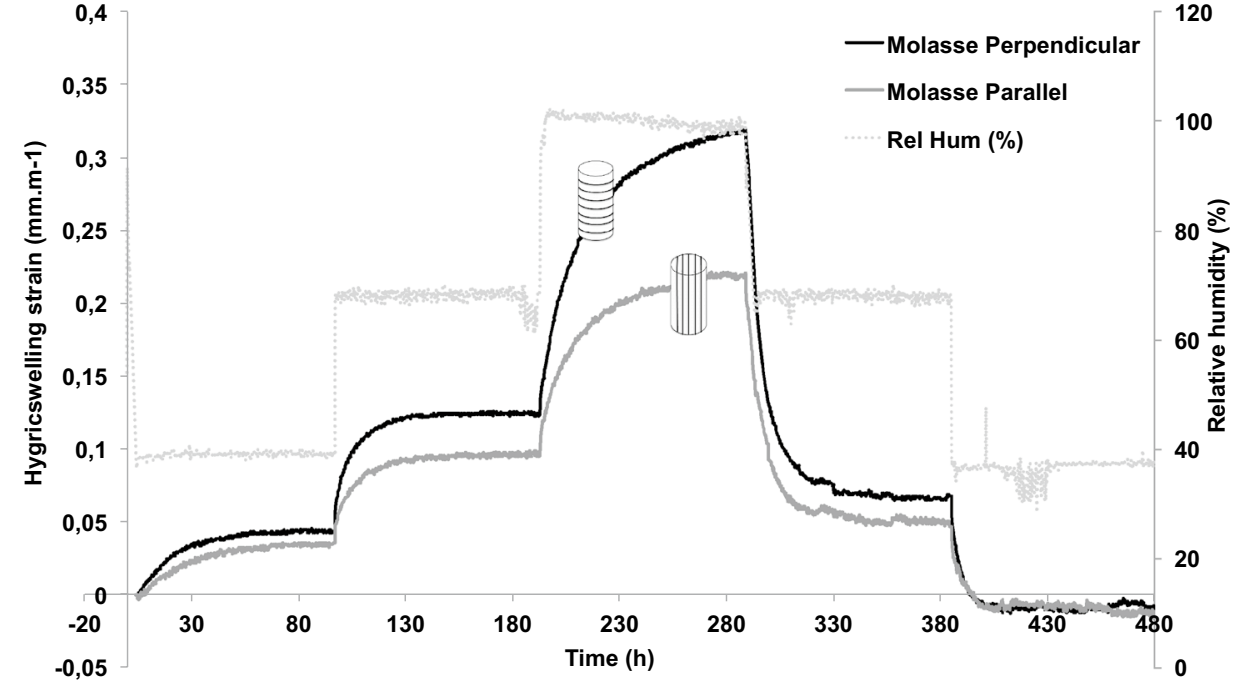


been described in Tiennot (2017). An anisotropic swelling behaviour is identified for these two sedimentary stones, as $\varepsilon_{\text {perpendicular }}$ is higher at each RH level than $\varepsilon_{\text {parallel }}$. It should also be noted that this swelling strain anisotropy increases from 33 to $97 \%$ of $\mathrm{RH}$.

Another result is the lower strain values reached during the drying phase. Indeed, at a given RH level, $\varepsilon_{\text {drying }}$ is lower than $\varepsilon_{\text {humidification }}$. The gradient of induced strains between two RH levels is higher during the drying phase. This swelling ability of the stones is related to the nature and distribution of the clay phases.

The influence of such anisotropic swelling behaviour and of the values discrepancy between humidification and drying phases on the mechanical behaviour are presented and discussed in the section below.

\section{Evolution of the Elastic Properties with Moisture Content}

\subsection{Humidification}

Young moduli are measured along the two principal directions of the sedimentary stones, $\mathbf{e}_{\mathbf{n}}$ and $\mathbf{e}_{\mathbf{t}}$. At the initial dry state, the moduli of Villarlod molasse are $E_{n}=8.43(0.39) \mathrm{GPa}$ and $E_{t}=10.7(0.17) \mathrm{GPa}$ (Table 2). For the sandstone, $E_{n}=13.2(0.70) \mathrm{GPa}$ and $E_{t}=14.4(0.94) \mathrm{GPa}$ (Table 3). The modulus $E_{n}$ is lower than $E_{t}$, which is relevant with the orientation of microcracks and minerals (Homand et al. 1993).

Under moisture, a significant loss of moduli in the two principal directions is identified and results indicate a decrease up to $69 \%$ at $\mathrm{RH}=97 \%$ for the Villarlod molasse. However, the evolution is quite different for the two stones. Indeed, both elastic moduli of Villarlod molasse are affected as soon as the RH increases (Table 2). At RH $=33 \%, E_{n}$ modulus decreases up to $47 \%$. Few modifications are then

Table 2 Young moduli of Villarlod molasse in both principal directions during humidification with estimation of the decrease of the value from the initial state, and during drying

\begin{tabular}{lllll}
\hline Molasse & $E_{\perp}$ & $\%$ of loss & $E_{/ /}$ & $\%$ of loss \\
\hline $\begin{array}{l}\text { Humidification } \\
\text { Initial }\end{array}$ & $8.43(0.39)$ & & $10.7(0.17)$ & \\
$\mathrm{RH}=33 \%$ & $4.46(0.17)$ & 47 & $6.81(0.21)$ & 36 \\
$\mathrm{RH}=65 \%$ & $4.39(0.30)$ & 48 & $6.22(0.38)$ & 42 \\
$\mathrm{RH}=97 \%$ & $2.61(0.20)$ & 69 & $3.86(0.33)$ & 64 \\
Drying & & & & \\
$\mathrm{RH}=65 \%$ & $4.59(0.03)$ & & $6.27(0.16)$ & \\
$\mathrm{RH}=33 \%$ & $4.98(0.16)$ & & $6.72(0.16)$ & \\
1 cycle & $6.78(0.12)$ & & $9.00(0.71)$ & \\
\hline
\end{tabular}

Table 3 Young moduli of Thüringer sandstone in both principal directions during humidification with estimation of the decrease of the value from the initial state, and during drying

\begin{tabular}{llclc}
\hline Sandstone & $E_{\perp}$ & $\%$ of loss & $E_{/ /}$ & $\%$ of loss \\
\hline $\begin{array}{l}\text { Humidification } \\
\text { Initial }\end{array}$ & $13.2(0.70)$ & & $14.4(0.94)$ & \\
RH=33\% & $13.0(0.17)$ & 2 & $13.1(0.10)$ & 9 \\
RH=65\% & $11.9(0.27)$ & 10 & $10.6(0.50)$ & 20 \\
RH=97\% & $5.20(0.66)$ & 61 & $6.33(0.33)$ & 56 \\
Drying & & & & \\
RH $=65 \%$ & $13.7(0.14)$ & & $11.4(0.83)$ & \\
RH $=33 \%$ & $13.4(0.09)$ & & $13.0(0.20)$ & \\
1 cycle & $14.8(0.04)$ & & $13.5(0.02)$ & \\
\hline
\end{tabular}

measured between 33 and $65 \%$ of $\mathrm{RH}$, and a new significant decrease is measured between 65 and $97 \%$ of RH.

On the contrary, Thüringer sandstone is not affected in the same manner (Table 3). The moduli are barely affected under $65 \%$ of $\mathrm{RH}$, and the significant decrease is measured between 65 and $97 \%$ of RH.

These results quantify the known evolution of Young moduli with the increase of moisture content. Moreover, they illustrate the differences in the elastic behaviour of the two stones and the fact that Villarlod molasse is affected even for low moisture content. This is related to the nature of the mineralogical phases. Indeed, molasse main clay phases, smectite and glauconite, are both very sensitive to moisture. It appears with these results that they are involved in the loss of elastic properties at very low moisture content. On the contrary, the clay phases in the sandstone are not affected at the same humidity state and samples have to be conditioned at RH higher than $65 \%$ to suffer a significant moduli loss.

\subsection{Drying Mechanisms Impact on Elastic Moduli}

To characterize the elastic properties evolution over a complete cycle of moisture content variations, the influence of $\mathrm{RH}$ decrease on samples first conditioned at $97 \%$ of $\mathrm{RH}$ is studied.

For the Villarlod molasse, the two moduli increase as a result of RH decrease from $97 \%$ to the dry state. It should be noted that the value of both moduli $E_{t}$ and $E_{n}$ is more important for a given RH state during the drying phase than the humidification. For instance, $E_{65 \% \text { drying }}$ is higher than $E_{65 \% \text { humid }}$. This can be related to the free swelling strains (Fig. 8). As a matter of fact, it is underlined that $\varepsilon_{s-\text { drying }}$ reaches lower values during the shrinkage. The recovering of this mechanical property is in close correlation with the elimination of water molecules from the network and the minerals sensitive to moisture. As the swelling strains in the two directions indicate the important gradient induced 
during drying, the slightly improved values of both moduli during drying seem relevant.

On the other hand, the Thüringer sandstone behaviour is more complicated. Indeed, the first result shows the inversion of its anisotropy. At $65 \%$ of RH of the drying phase, $E_{n}$ becomes higher than $E_{t}$. Moreover, at $33 \%$ of $\mathrm{RH}, E_{n}$ remains lower despite the decrease of moisture content. This indicates that deformation of this sandstone phases are highly different-for instance, between quartz and clay phases-and requires a microcracking evolution. Initiation of a drying-induced microcracking is highlighted. As $E_{n}$ is more affected, these induced microcracks are generated along $\mathbf{e}_{\mathbf{t}}$, the inherent microcracks plane (Bargellini et al. 2006). This is relevant with the result as obtained after several cycles of RH variations (Tiennot et al. 2017). Such microcracking can appear to relax the stresses induced during the drying shrinkage (Bazănt and Raftshol 1982). Thus, clay phases nature and distribution influence the swelling and consequently the elastic behaviour of stones.

\section{Evolution of Toughness}

\subsection{Behaviour at the Initial State}

Fracture behaviour and toughness are studied with respect to the natural anisotropy of the stones. Both stones show a quasi-brittle and brittle behaviour (Figs. 9, 10) with a slow crack propagation for the Villarlod molasse and a really fast for the Thüringer sandstone.

From the initial dry state, samples present different fracture behaviours. Toughness values reached in each configuration are lowest for the molasse than for the sandstone (Tables 4, 5). First, Villarlod molasse shows an anisotropic behaviour at the initial state, as SCBperp, $\mathrm{SCBn}$, and SCBt values differ from each other (Fig. 9 and Table 4). SCBt is lower, indicating that initiation occurs more easily along the isotropy transverse plane. On the contrary, the Thüringer sandstone toughnesses SCBn and
Fig. 9 Villarlod molasse fracture behaviour using SCB method with respect to the stone natural orientation

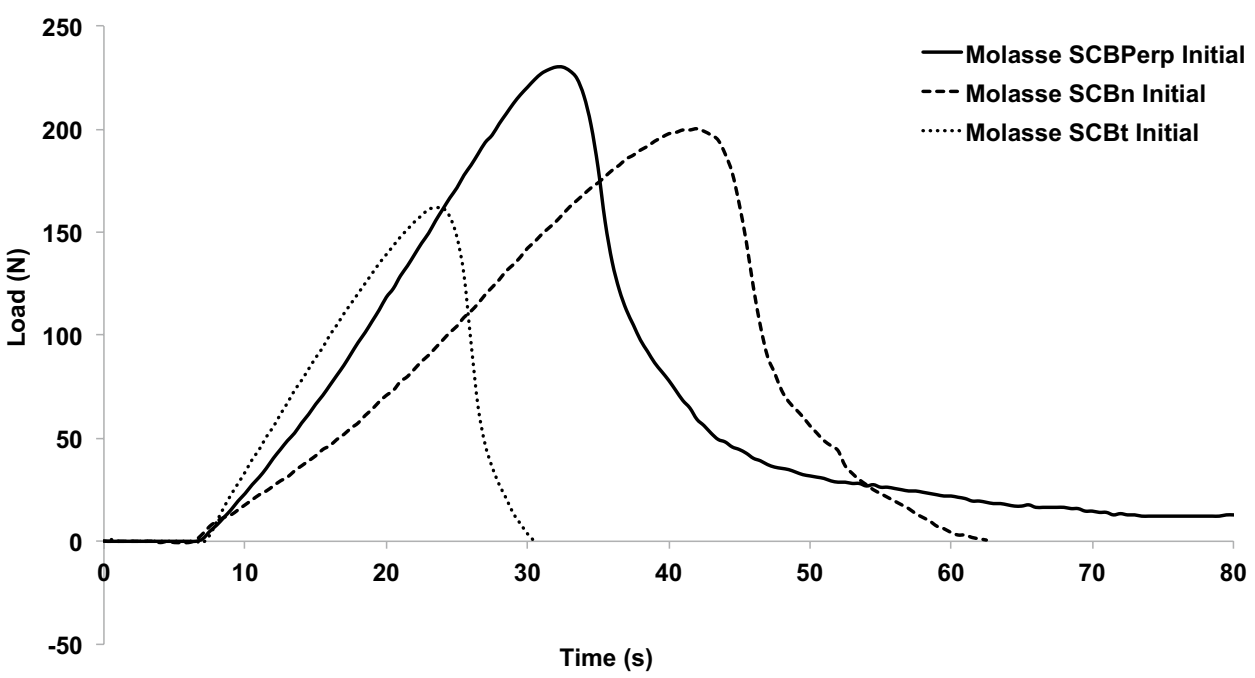

Fig. 10 Thüringer sandstone fracture behaviour using SCB method with respect to the stone natural orientation

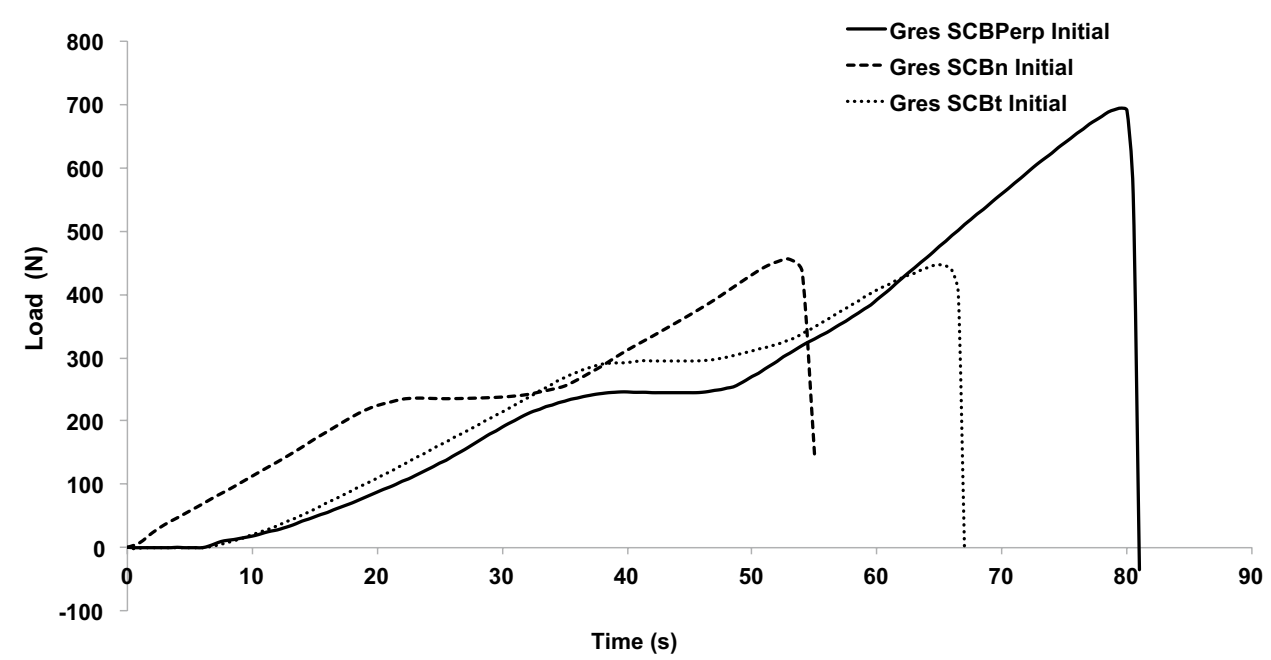


SCBt are identical at the initial state, so that no preferred orientation is highlighted for crack initiation (Fig. 10 and Table 5). Evolution of the stones toughness under various $\mathrm{RH}$ conditions is then studied.

\subsection{Evolution with Increase of Water Vapour Pressure}

Several papers presented the influence of water vapour pressure on toughness of stone (Utagawa et al. 1999; Nara et al. 2011, 2012). Some of them proposed to follow the dependency of $K_{I C}$ with the water vapour pressure $p$ using the equation:

$K_{\mathrm{IC}}=\beta p^{-m}$,

where $\beta$ is a constant for $p=1 \mathrm{~Pa}$ and $m$ the slope of the line on the logarithmic graph (Kuruppu et al. 2010; Kataoka et al. 2014). The resistance to the initiation of crack is more affected by water vapour pressure when $m$ reaches high values.

In this research, when RH increases, the three toughnesses SCBperp, SCBn, and SCBt of the molasse and the sandstone decrease. This phenomenon has already been observed, and is due to the water condensation effect at the crack tip (Atkinson 1982).

However, the influence of moisture content and of the induced swelling on the mechanical behaviour of the two stones is different. The evolution of the sandstone toughness has already been presented in Tiennot et al. (2017). SCBn and SCBt values measured during humidification indicate that an anisotropy of fracture toughness appears when the moisture content increases (Fig. 11). Indeed, values of SCBn and SCBt remain equal at $\mathrm{RH}=33 \%$, and when $65 \%$ are reached, anisotropy appears and remains at $97 \%$ of RH. SCBt samples are more affected by the RH increase than SCBn, as the $m$ parameter is higher. The opening of

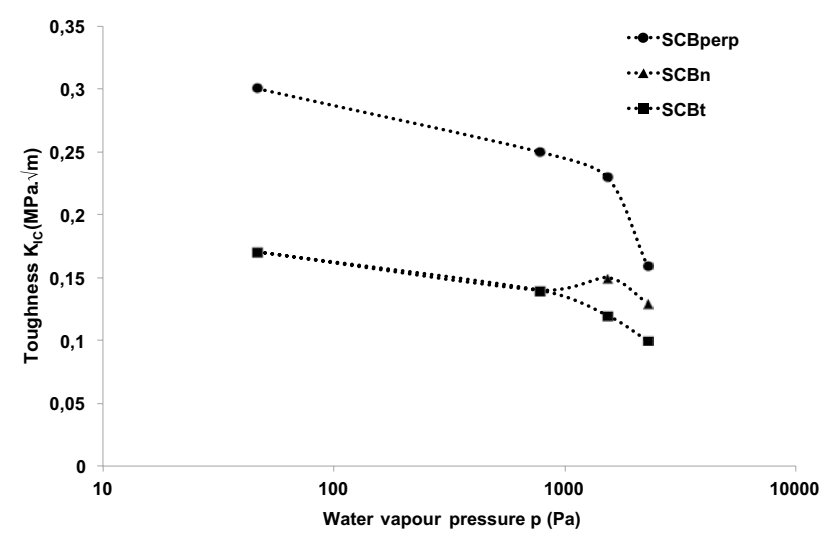

Fig. 11 Toughness evolution of Thüringen sandstone with water vapour pressure with respect to the stone natural orientation microcracks, as previously described, along the $\mathbf{e}_{\mathbf{t}}$ axis is relevant with the identified anisotropy of toughness. Thus, oriented swelling influences the toughness with respect to the orientation of the phases.

Villarlod molasse toughness evolution is described in Table 4 and Fig. 12. At the initial dry state, the values of $K_{\mathrm{IC}}$ in the three configurations differ from each other. When water vapour pressure increases SCBn and SCBt both decrease in the same manner until $65 \%$ of RH. However, when the samples are conditioned at $\mathrm{RH}=97 \%$, the three fracture toughnesses decrease and reach the same value of $0.05 \mathrm{MPa} \cdot \sqrt{m}$ (Table 4). Under this high water vapour pressure and thus this high free swelling of the material, the ability of the stone to withstand crack propagation is the same perpendicular and parallel to the natural orientation

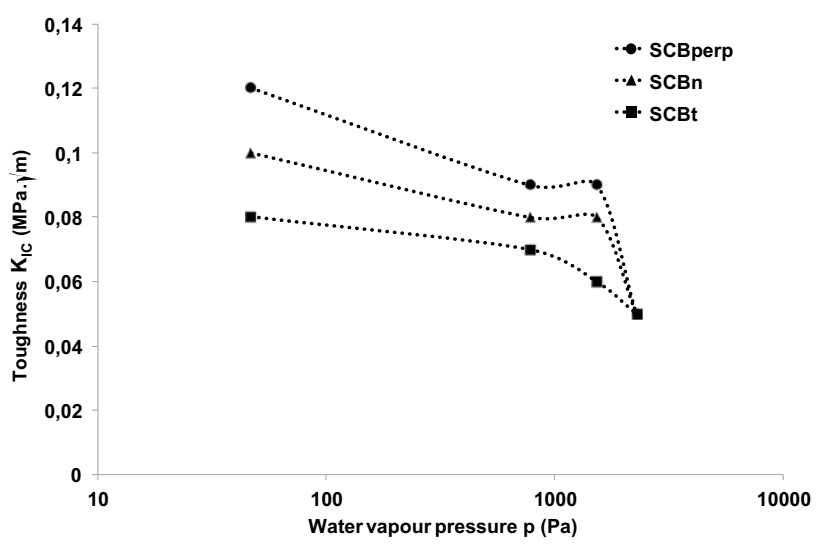

Fig. 12 Toughness evolution of Villarlod molasse with water vapour pressure with respect to the stone natural orientation

Table 4 Fracture toughness of molasse for the three configurations at the initial dry state and at different $\mathrm{RH}$ states: $\mathrm{RH}=33-65-97 \%$, during humidification and drying

\begin{tabular}{llll}
\hline$K_{\mathrm{IC}}(\mathrm{MPa} \cdot \sqrt{m})$ & SCBperp & SCBn & SCBt \\
\hline Initial dry & $0.12(0.02)$ & $0.10(0.03)$ & $0.08(0.02)$ \\
$\mathrm{RH}=33 \%$ & $0.09(0.01)$ & $0.08(0.01)$ & $0.07(0.01)$ \\
$\mathrm{RH}=65 \%$ & $0.09(0.01)$ & $0.08(0.00)$ & $0.06(0.03)$ \\
$\mathrm{RH}=97 \%$ & $0.05(0.01)$ & $0.05(0.04)$ & $0.05(0.01)$ \\
$m$ & 0.165 & 0.130 & 0.102 \\
$\beta$ & 0.24 & 0.17 & 0.12 \\
$R^{2}$ & 0.62 & 0.61 & 0.77 \\
$\mathrm{RH}=97 \%$ & $0.05(0.01)$ & $0.05(0.04)$ & $0.05(0.01)$ \\
$\mathrm{RH}=65 \%$ & $0.08(0.02)$ & $0.06(0.01)$ & $0.06(0.01)$ \\
$\mathrm{RH}=33 \%$ & $0.09(0.02)$ & $0.07(0.01)$ & $0.06(0.01)$ \\
$1 \mathrm{cycle}$ & $0.13(0.03)$ & $0.12(0.03)$ & $0.09(0.02)$ \\
$m$ & 0.199 & 0.198 & 0.139 \\
$\beta$ & 0.30 & 0.26 & 0.15 \\
$R^{2}$ & 0.78 & 0.91 & 0.95 \\
\hline
\end{tabular}


Table 5 Fracture toughness of sandstone for the three configurations for the initial dry state and for different RH states: $\mathrm{RH}=33-65-97 \%$, during humidification and drying

\begin{tabular}{llll}
\hline$K_{\mathrm{IC}}(\mathrm{MPa} \cdot \sqrt{m})$ & SCBperp & SCBn & SCBt \\
\hline Initial dry & $0.30(0.04)$ & $0.17(0.03)$ & $0.17(0.04)$ \\
$\mathrm{RH}=33 \%$ & $0.25(0.03)$ & $0.14(0.03)$ & $0.14(0.02)$ \\
$\mathrm{RH}=65 \%$ & $0.23(0.03)$ & $0.15(0.02)$ & $0.12(0.01)$ \\
$\mathrm{RH}=97 \%$ & $0.16(0.01)$ & $0.13(0.02)$ & $0.10(0.03)$ \\
$m$ & 0.124 & 0.057 & 0.118 \\
$\beta$ & 0.50 & 0.21 & 0.28 \\
$R^{2}$ & 0.67 & 0.78 & 0.84 \\
$\mathrm{RH}=97 \%$ & $0.16(0.01)$ & $0.13(0.02)$ & $0.10(0.03)$ \\
$\mathrm{RH}=65 \%$ & $0.23(0.01)$ & $0.18(0.02)$ & $0.17(0.02)$ \\
$\mathrm{RH}=33 \%$ & $0.21(0.01)$ & $0.14(0.02)$ & $0.12(0.04)$ \\
$1 \mathrm{cycle}$ & $0.32(0.05)$ & $0.23(0.03)$ & $0.18(0.06)$ \\
$m$ & 0.147 & 0.122 & 0.103 \\
$\beta$ & 0.57 & 0.36 & 0.27 \\
$R^{2}$ & 0.81 & 0.68 & 0.41 \\
\hline
\end{tabular}

of minerals and microcracks. The swelling of the sensitive minerals, especially smectite and glauconite, annihilates the initial anisotropy of the fracture behaviour of molasse (Fig. 12).

It should also be noted that molasse $m$ parameters reach higher values than the sandstone. This indicates that the increase of moisture content affects more significantly the first stone. This may also be explained by the mineralogical differences and by the swelling ability of each phase. Thus, the two stones show a different behaviour in close correlation with the nature and accessibility of the mineralogical phases and their swelling ability has a direct impact on the macroscopic mechanical behaviour.

\subsection{Evolution with Decrease of Water Vapour Pressure}

Evolution of toughness during drying is then verified. The reversibility of the behaviour is observed for the Villarlod molasse. Toughness values are recovered, while RH decreases (Table 4). The temporary isotropy at $\mathrm{RH}=97 \%$ of the molasse, and moreover, the reversibility of this behaviour is related to the highly sensitive to moisture phases smectite and glauconite.

On the contrary, the sandstone anisotropy measured for RH values higher than $65 \%$ remains during the drying. A preferred initiation orientation appears within the sandstone after a complete RH cycle. This indicates that the phases affected and involved in the swelling are not able to recover their initial conditions. Indeed, as previously discussed in Tiennot et al. (2017), the evolution of SCBt and SCBn illustrates the creation of drying shrinkage microcracks along the $\mathbf{e}_{\mathbf{t}}$ axis. Anisotropy, in close correlation with the mineralogical phase distribution and nature, evolves and influences the fracture behaviour of the two stones.

While the clay matrix of molasse is able to sustain the free hygric swelling, the sandstone matrix needs to relax the stresses caused by drying, inducing a modification of the microcracks network. Thus, mineralogical phases have direct consequences on the fracture behaviour of the stone during the drying.

It should also be noted that the two stones are more affected by the drying after a $97 \%$ conditioning, as illustrated by the higher $m$ parameter values during this phase. This is relevant with the evolution of the swelling behaviour during humidification and drying. This is useful to understand the influence of humidification and drying on the scaling effect.

\subsection{Influence of Clay Minerals on Fracture Behaviour}

The SCB samples tested to measure the toughness of the stones are observed after crack propagation. Clay phases are assumed to be the weakness phases of the stones. This is confirmed by the crack paths followed within the stone.

Optical microscope and FESEM images analysis indicates that intergranular paths are followed within the two sedimentary stones (Figs. 13, 14). Crack gets around and along the most rigid grain boundaries as quartz and feldspars of both stones, and propagates within the smectite phases of molasse (Figs. 6, 13) and the calcitic and clay matrix of the sandstone (Fig. 14). In the flexible smectitic matrix of molasse, grain boundaries marks can even be observed after the crack propagation (Fig. 15). Intergranular decohesion of glauconite spots when the principal crack propagates along them also indicates the weakness of these clay minerals (Fig. 16).

These results and observations illustrate that failure occurs in the plane, where clay phases are located and that fracture patterns follow these minerals orientation. Clay phases are the preferred planes of propagation.

\section{Conclusion}

To better understand the influence of clay minerals on the monumental stone degradation, two sedimentary stones with different specific mineralogical compositions and distributions are studied. The clay phases are identified as smectite and glauconite for the Villarlod molasse and as chlorite and interlayers of smectite-chlorite for the Thüringer sandstone. These clay phases are different for both stones and provide various mechanical and fracture behaviour. The evolution of Young moduli and toughness with moisture content and with respect to the natural orientation of the stones are studied. 

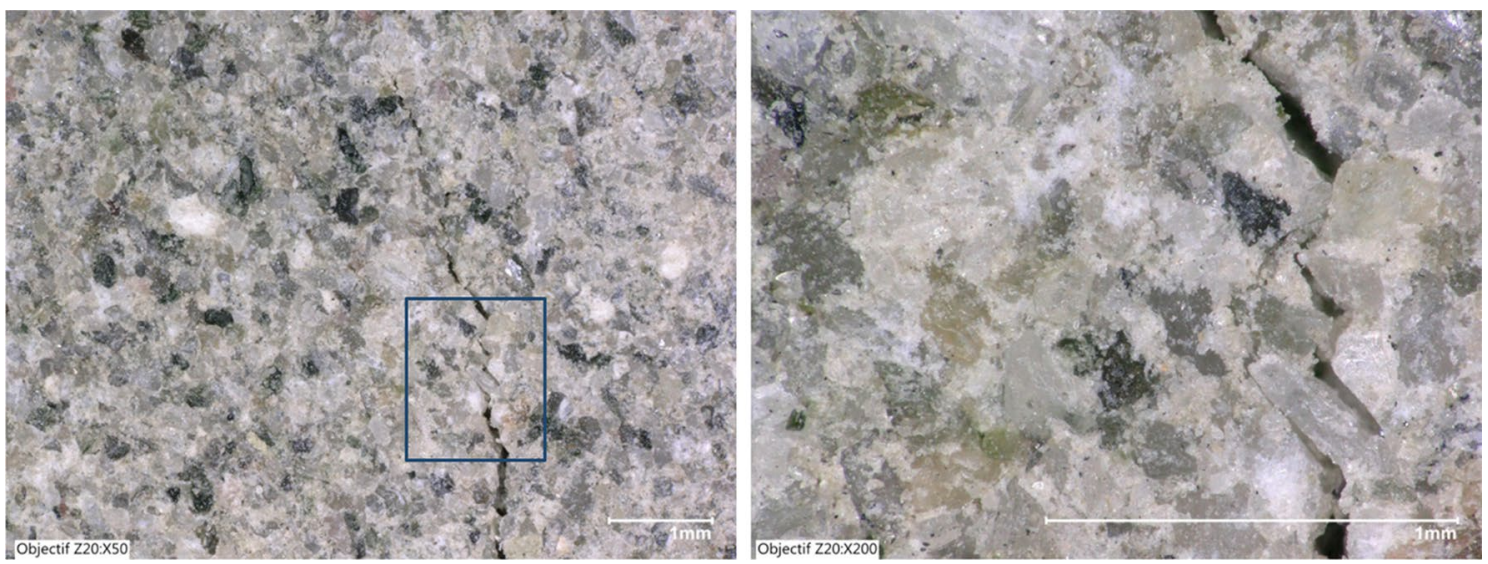

Fig. 13 Crack paths in SCB sample of Villarlod molasse, details of intergranular propagation along the rigid grains boundaries and within the clayey matrix
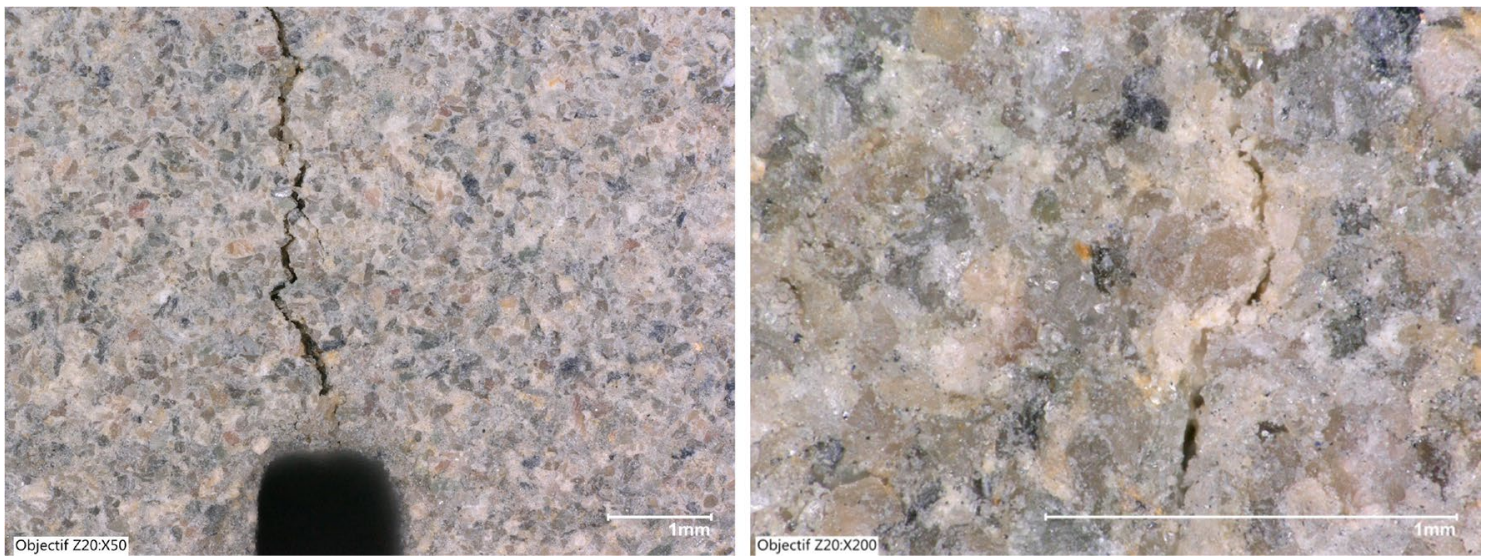

Fig. 14 Crack paths in SCB sample of Thüringen sandstone, details of propagation within the calcitic and clayey matrix
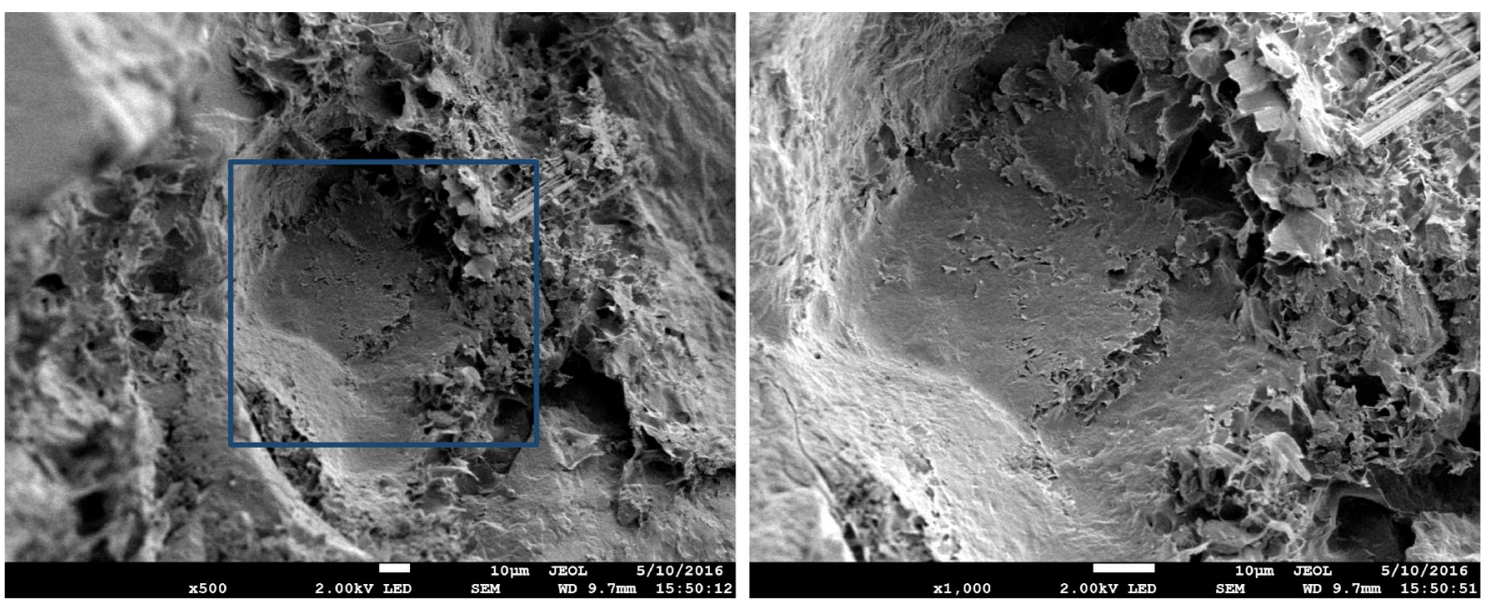

Fig. 15 Fracture surfaces of Villarlod molasse, details of a grain print included in the weakness smectite phase 

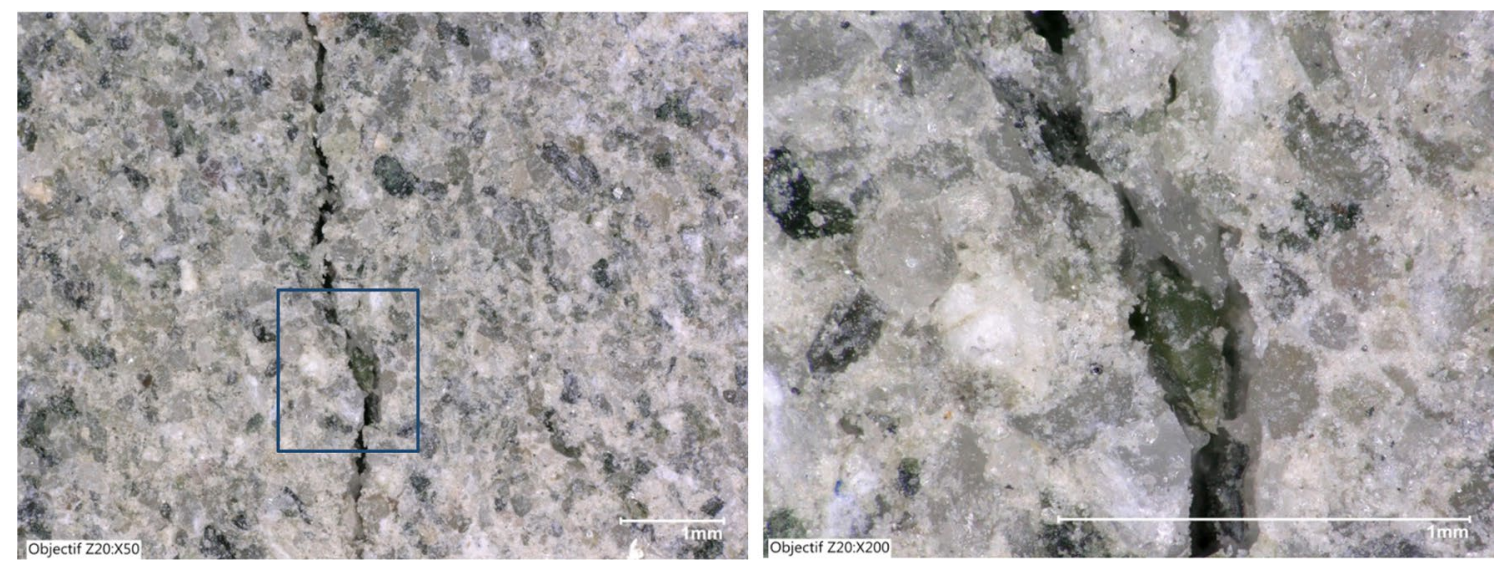

Fig. 16 Crack paths in SCB sample of Villarlod molasse, details of the decohesion of the weak glauconite spot as a consequence of propagation

Smectite and glauconite induce a decrease of moduli as soon as $\mathrm{RH}=33 \%$ is reached, while the clay matrix of the sandstone is significantly affected at higher RH. This is of main interest, as the decrease of moduli is involved in the natural decay of the stone under exposure conditions. The fracture behaviour is also largely influenced by the nature and distribution of clay minerals during RH variations. At the initial dry state, anisotropy of molasse toughness is measured and is annihilated at $\mathrm{RH}=97 \%$. No preferred orientation of initiation is measured at high RH content. On the contrary, the sandstone suffers from an oriented microcracking creation, inducing a new anisotropy. Such evolution of the toughness value and of the fracture behaviour with moisture content is in close correlation with the clay phases of the two sedimentary stones and their own sensitivity to moisture. These specific platy minerals are also directly involved in the cracking processes. They are identified as the weakness planes of the stones and the preferred planes of initiation and propagation of crack.

Acknowledgements This work was supported by the French state funds managed by the ANR within the Investissements d'Avenir programme under reference ANR-11-IDEX-0004-02, and more specifically within the framework of the Cluster of Excellence MATISSE led by Sorbonne Universités.

Open Access This article is distributed under the terms of the Creative Commons Attribution 4.0 International License (http://creativeco mmons.org/licenses/by/4.0/), which permits unrestricted use, distribution, and reproduction in any medium, provided you give appropriate credit to the original author(s) and the source, provide a link to the Creative Commons license, and indicate if changes were made.

\section{References}

Amadei B (1996) Importance of anisotropy when estimating and measuring in situ stresses in rock. Int J Rock Mech Min Sci Geomech Abstr 33(3):293-325

Aristégui C, Baste S (1997) Optimal recovery of the elasticity tensor of general anisotropic materials from ultrasonic velocity data. $\mathrm{J}$ Acoust Soc Am 101(2):813-833

ASTM (2010) Astm standard d4404-10standard test method for deterioration of pore volume and pore volume distribution of soil and rock by mercury intrusion porosimetry. West Conshohocken, PA, USA

Atkinson BK (1980) Stress corrosion and the rate-dependent tensile failure of a fine-grained quartz rock. Tectonophysics 60(3):281-290

Atkinson BK (1982) Subcritical crack propagation in rocks: theory, experimental results and applications. J Struct Geol 4(1):41-56

Baecher GB, Einstein HH (1961) Size effect in rock testing. Geophys Res Lett 8(7):671-674

Bargellini R, Halm D, Dragon A (2006) Modelling of anisotropic damage by microcracks: towards a discrete approach. Arch Mech 58(2):93-123

Bazănt ZP, Raftshol WJ (1982) Effect of cracking in drying and shrinkage specimens. Cem Concr Res 12(2):209-226

Burshtein LS (1969) Effect of moisture on the strength and deformability of sandstone. Sov Min 5(5):573-576

Erguler Z, Ulusay R (2009) Water-induced variations in mechanical properties of clay-bearing rocks. Int J Rock Mech Min Sci 46(2):355-370

Felix C (1977) Molasses et grès de villarlod (fribourg). Technical report, LCP

Felix C (1983) Sandstone linear swelling due to isothermal water sorption. Mater Sci Restor 1:305-310

Felix C, Ferrari P, Queisser A (2000) Déconsolidation par absorption d'eau de grès traités avec le silicate d'éthyle. Mesures non destructives de e, $\mathrm{g}$ et $\mathrm{v}$. In: 9th international congress on deterioration and conservation of stone: proceedings vol $2, \mathrm{pp}$ 287-295

Franzen C, Mirwald PW (2004) Moisture content of natural stone: static and dynamic equilibrium with atmospheric humidity. Environ Geol 46(3):391-401

Funatsu T, Seto M, Shimada H, Matsui K, Kuruppu M (2004) Combined effects of increasing temperature and confining pressure 
on the fracture toughness of clay bearing rocks. Int J Rock Mech Min Sci 41(6):927-938

Guy N, Seyedi DM, Hild F (2018) Characterizing fracturing of clay-rich lower watrous rock: from laboratory experiments to nonlocal damage-based simulations. Rock Mech Rock Eng 51(6): $1777-1787$

Hawkins A, McConnell B (1992) Sensitivity of sandstone strength and deformability to changes in moisture content. Q J Eng Geol 25:115-130

Homand F, Morel E, Henry J-P, Cuxac P, Hammade E (1993) Characterization of the moduli of elasticity of an anisotropic rock using dynamic and static methods. Int J Rock Mech Min Sci Geomech Abstr 30(5):527-535

ICOMOS (2008) Glossaire illustré sur les formes d'altération de la pierre. International Scientific Committee for Stone (ISCS). ICOMOS et ISCS, Paris

Kataoka M, Obara Y, Kuruppu M (2014) Estimation of fracture toughness of anisotropic rocks by semi-circular bend (SCB) tests under water vapor pressure. Rock Mech Rock Eng 48(4):1353-1367

Kuruppu M, Obara Y, Kataoka M (2010) Determination of fracture toughness of anisotropic rocks under water vapour pressure by semi-circular bend test. In: Topal E, Kuruppu M (ed) Mine planning \& equipment selection. The Australasian Institute of Mining and Metallurgy (AusIMM), Perth, WA, pp 599-610

Lim I, Johnston I, Choi S (1993) Stress intensity factor for semicircular specimens under three-point bending. Eng Fract Mech 44:363-382

Meredith PG, Atkinson BK (1983) Stress corrosion and acoustic emission during tensile crack propagation in whin sill dolerite and other basic rocks. Geophys J R Astron Soc 75:1-21

Mertz J-D, Guiavarc'h M, Pagnin P (2012) Dilation behaviour of lime mortars for restoration work: application to the compatibility of cracked stone reassembling. Eur J Environ Civ Eng 16(5):527-542

Nara Y, Morimoto K, Yoneda T, Hiroyoshi N, Kaneko K (2011) Effects of humidity and temperature on subcritical crack growth in sandstone. Int J Solids Struct 48(7-8):1130-1140

Nara Y, Morimoto K, Hiroyoshi N, Yoneda T, Kaneko K, Benson PM (2012) Influence of relative humidity on fracture toughness of rock: implications for subcritical crack growth. Int J Solids Struct 49(18):2471-2481

Sarout J (2006) Propriétés physiques et anisotropie des roches argileuses : modélisation micromécanique et expériences triaxiales. Ph.D. thesis, Université Paris 11 Orsay
Scherer G, Jiménez González I (2005) Characterization of swelling in clay-bearing stone. In: Stone decay in the architectural environment, vol 390. Geological Society of America Special Paper, pp $51-61$

Siegesmund S, Snethlage R (2011) Stone in architecture: properties, durability. Springer, Berlin

Siggins A (1993) Dynamic elastic tests for rock engineering, vol 3. Pergamon press, Oxford, pp 601-618

Stück H (2013) Dimensional Sandstones: Weathering Phenomena, Technical Properties and Numerical Modeling of Water Migration. Ph.D. thesis, Georg-August-Universität Göttingen

Tiennot M (2017) Inlfuence des propriétés physico-mécaniques de minéraux argileux dans l'altération de la pierre monumentale. Ph.D. thesis, Université Pierre et Marie Curie Paris 6

Tiennot M, Bourgès A (2016) Evaluation of small core-based specimens for characterization of stone deterioration. Int J Rock Mech Min Sci 84:69-73

Tiennot M, Mertz J-D, Bourgès A (2017) Influence of anisotropic microcracking due to swelling on the fracture toughness of a clay-bearing sandstone. Rock Mech Rock Eng 50(11):2861-2870

Tutluoglu L, Keles C (2011) Mode i fracture toughness determination with straight notched disk bending method. Int J Rock Mech Min Sci 48:1248-1261

Utagawa M, Seto M, Kosugi M, Katsuyama K, Matsui K (1999) The evaluation of fracture toughness of rock in wet and chemical condition. In: Proceedings of ' 99 Japan-Korea joint symposium on rock engineering, Fukuoka, Japan, pp 573-578

Van Eeckhout EM (1976) The mechanisms of strength reduction due to moisture in coal mine shales. Int J Rock Mech Min Sci Geomech Abstr 13(2):61-67

Vasarhelyi B (2003) Some observations regarding the strength and deformability of sandstones in dry and saturated conditions. Bull Eng Geol Environ 62(3):245-249

Wangler T, Scherer GW (2008) Clay swelling mechanism in claybearing sandstones. Environ Geol 56(3):529-534

Publisher's Note Springer Nature remains neutral with regard to jurisdictional claims in published maps and institutional affiliations. 